\title{
A expansão no Ensino Superior a Distância em Mato Grosso do Sul, no período de 2000 a 2012
}

Carla Busato Zandavalli Maluf de Araujo ${ }^{a}$

\section{Resumo}

Neste artigo, buscou-se analisar a forma da expansão dos cursos de graduação a distância, no Estado de Mato Grosso do Sul (MS), bem como caracterizar os tipos de cursos de graduação ofertados na modalidade a distância, nas instituições públicas e privadas, em Mato Grosso do Sul, e verificar o acesso e a equidade da oferta de cursos, nas diferentes áreas do conhecimento. Foram efetivadas, até o momento, duas etapas da pesquisa, abrangendo o levantamento da expansão dos cursos de graduação a distância, no Brasil e em Mato Grosso do Sul, de 2000 a 2012, por meio da análise dos dados do Censo da Educação Superior, atos normativos, informações nas bases oficiais do MEC e dados institucionais. Parte-se da perspectiva de que a expansão analisada está condicionada pelos aspectos macroeconômicos e pela forma de organização do Estado brasileiro, em face às determinações do capital. Os resultados obtidos apontam para o fato de que o ingresso aos cursos de graduação foi efetivamente instituído, com a oferta de cursos em todas as microrregiões do Estado de Mato Grosso do Sul, mas, de forma mais significativa, em instituições privadas e concentrada em poucas áreas de conhecimento, o que não caracteriza a efetiva democratização do acesso. Palavras-chave: Educação a Distância. Cursos de graduação. Expansão. Mato Grosso do Sul.

\section{Introdução}

Os dados disponibilizados por meio do Censo da Educação Superior, a partir de 2000, denotam um processo acentuado de expansão da Educação a Distância $(\mathrm{EaD})$ e uma expansão diferenciada daquela que ocorreu no ensino presencial, nos anos 1990 e 2000, na medida em que houve predomínio inicial da oferta

\footnotetext{
a Universidade Federal de Mato Grosso do Sul - UFMS - Coordenadoria de Educação Aberta e a Distância. Campo Grande, Mato Grosso do Sul, Brasil.
} 
da graduação a distância, por parte de universidades públicas e em cursos de licenciatura. Os dados mais recentes indicam a preponderância da oferta de vagas e de matrículas no ensino privado, mas ainda com ênfase da oferta de licenciaturas em universidades (BRASIL, 2013a).

Tal processo se deu em face do credenciamento de Instituições de Educação Superior para a oferta de cursos na modalidade a distância e da regulamentação da Lei n. ${ }^{\circ}$ 9.394, de 20 de dezembro de 1996, que institui a modalidade, bem como da intencionalidade do Estado brasileiro em ampliar as taxas de escolarização neste nível de ensino e em regiões nas quais não se conta com a possibilidade efetiva de oferta, tanto no âmbito público como no setor privado. No âmbito privado, o crescimento bastante significativo ocorreu em instituições de grande porte, com potencial financeiro suficiente para desenvolver o ensino mediado pelas tecnologias, especialmente os grandes grupos corporativos, que trouxeram ao cenário nacional, a partir dos anos 2000, a figura das empresas educacionais vinculadas a fundos de ações na bolsa de valores.

Neste artigo, que apresenta resultados parciais de dois projetos de pesquisa ${ }^{1}$, buscou-se analisar o perfil desta expansão no Estado de Mato Grosso do Sul, situado na Região Centro-Oeste, que apesar dos bons níveis de escolarização líquida e bruta na educação superior, ainda apresenta problemas de acesso a este nível de ensino, dada a concentração da oferta em alguns municípios e as condições geográficas do Estado, por contar com grandes distâncias entre municípios, bem como situações adversas para o deslocamento nas regiões pantanosas.

Como objetivos específicos da pesquisa, no eixo sobre a educação superior a distância, situam-se: a) caracterizar os tipos de cursos de graduação ofertados na modalidade a distância, nas instituições públicas e privadas, em Mato Grosso do Sul; b) verificar a equidade da oferta de cursos, nas diferentes áreas do conhecimento; c) analisar o acesso, a permanência e a terminalidade nos cursos de graduação a distância no Estado de Mato Grosso do Sul; d) identificar as políticas públicas desenvolvidas para a expansão da modalidade a distância e suas formas de financiamento.

\footnotetext{
${ }^{1} \mathrm{O}$ estudo é parte da pesquisa "Política e educação na primeira década do século XXI: a intersecção das ações do governo central com as dos governos sul-mato-grossenses", com fomento da Fundação de Apoio ao Desenvolvimento do Ensino, Ciência e Tecnologia do Estado de Mato Grosso do Sul (FUNDECT), por meio do Edital Chamada FUNDECT/CNPq N. ${ }^{\circ}$ 05/2011 - PPP, bem como do Projeto "A política educacional no contexto das relações federativas no Brasil", que conta com fomento do CNPq. Ambos os estudos encontram-se em andamento.
} 
Foram efetivadas, até o momento, duas etapas do estudo: o levantamento da expansão dos cursos de graduação a distância, nos dados oficiais do Estado Brasileiro, por meio do Censo da Educação Superior, de 2000 a 2012, e o levantamento da expansão destes cursos no Estado de Mato Grosso do Sul, no mesmo período, utilizando-se dos dados do Censo da Educação Superior, atos normativos, informações nas bases oficiais do MEC e informações disponibilizadas pelas instituições.

O artigo está estruturado em três partes, que tratam, respectivamente, da expansão da modalidade a distância nos cursos de graduação no Brasil, no período de 2000 a $2012^{2}$, da expansão em Mato Grosso do Sul, no mesmo período, seguidas de uma análise geral das condições identificadas.

\section{A expansão da modalidade a distância, na educação superior, nos anos 2000}

A expansão observada na educação a distância, nos anos 2000, é muito expressiva em todos os aspectos, nos âmbitos das instituições credenciadas, dos cursos oferecidos, das matrículas, das vagas e dos inscritos (Tabelas 1 e 2). O crescimento acumulado de instituições, no período de 2000 a 2012, foi de $2.042 \%$; de cursos, $16.300 \%$; de vagas, $20.575 \%$, e o de inscritos, $127.715 \%$.

Embora haja manutenção do crescimento de instituições e de cursos, observa-se decréscimo de vagas, inscritos e ingressos em 2003 - ano em que são publicados os Referenciais de Qualidade para a EaD - e em 2009, talvez como um possível reflexo dos processos de regulação do Estado, desenvolvidos de forma mais intensa a partir de 2008. O decréscimo se repete em 2010, quanto ao número de instituições, e em 2011, em relação à oferta de vagas.

A flutuação do crescimento quanto a número de instituições, oferta de vagas, inscritos, ingressos e concluintes, porém, torna-se elemento menor quando observado o avanço do número de cursos, que salta de sete, em 2000, para 1.148, em 2012, e das matrículas na modalidade, as quais, de menos de $1 \%$ em 2000, passam a representar $15,8 \%$ do total de matrículas na educação superior, que soma 7.037.688 matrículas em 2012, sendo 5.923.838 na modalidade presencial e 1.113.850 na modalidade a distância (Tabelas 2 e 3).

2 O período de 2000 a 2012 acompanha a disponibilidade de informações no Censo da Educação Superior, pois o primeiro registro da oferta da modalidade a distância em cursos de Graduação se deu em 2000 e a última, no Censo de 2012. 
Tabela 1 - Evolução do Número de IES, Cursos, Vagas e Inscritos na Educação a Distância Brasil - 2000 a 2012

\begin{tabular}{ccccccccc}
\hline Ano & IES & $\% \Delta$ & Cursos & $\% \Delta$ & Vagas & $\% \Delta$ & Inscritos & $\% \Delta$ \\
\hline 2000 & 7 & - & 7 & - & 6.430 & - & 8.002 & - \\
\hline 2001 & 10 & 42,8 & 10 & 42,8 & 6.856 & 6,6 & 13.967 & 74,5 \\
\hline 2002 & 25 & 150,0 & 46 & 360,0 & 24.389 & 255,7 & 29.702 & 112,6 \\
\hline 2003 & 38 & 52,0 & 52 & 13,0 & 24.025 & $-1,5$ & 21.873 & $-26,4$ \\
\hline 2004 & 47 & 23,7 & 107 & 105,8 & 113.079 & 370,7 & 50.706 & 131,8 \\
\hline 2005 & 73 & 55,3 & 189 & 76,6 & 423.411 & 274,4 & 233.626 & 360,7 \\
\hline 2006 & 77 & 5,5 & 349 & 84,7 & 813.550 & 92,1 & 430.229 & 84,2 \\
\hline 2007 & 97 & 26,0 & 408 & 16,9 & 1.541 .070 & 89,4 & 537.959 & 25,0 \\
\hline 2008 & 115 & 18,6 & 647 & 58,6 & 1.699 .489 & 10,3 & 708.784 & 31,8 \\
\hline 2009 & 224 & 94,7 & 844 & 30,4 & 1.561 .715 & $-8,1$ & 665.839 & $-6,0$ \\
\hline 2010 & 135 & $-39,7$ & 930 & 10,2 & 1.634 .118 & 4,6 & 690.921 & 3,7 \\
\hline 2011 & 142 & 5,18 & 1.044 & 12,2 & 1.224 .760 & $-25,0$ & 797.176 & 15,3 \\
\hline 2012 & 150 & 5,63 & 1.148 & 9,96 & 1.329 .407 & 8,54 & 1.029 .981 & 29,2 \\
\hline
\end{tabular}

Fonte: Brasil (2013b).

Nota: Tabela elaborada pela autora a partir dos dados obtidos na fonte acima indicada.

Tabela 2 - Evolução do Número de Ingressos, Matrículas e Concluintes na Educação a Distância - Brasil - 2002 a 2012

\begin{tabular}{ccccccc}
\hline Ano & Ingressos & $\% \Delta$ & Matrículas & $\% \Delta$ & Concluintes & $\% \Delta$ \\
\hline 2000 & 5.287 & - & 1.682 & - & 460 & - \\
\hline 2001 & 6.618 & 25,1 & 5.359 & 218,6 & 131 & $-71,5$ \\
\hline 2002 & 20.685 & 212,5 & 40.714 & 659,7 & 1.712 & $1.206,8$ \\
\hline 2003 & 14.233 & $-31,2$ & 49.911 & 22,6 & 4.005 & 133,9 \\
\hline 2004 & 25.006 & 75,7 & 59.611 & 19,4 & 6.746 & 68,4 \\
\hline 2005 & 127.014 & 407,9 & 114.642 & 92,3 & 12.626 & 87,2 \\
\hline 2006 & 212.465 & 67,3 & 207.206 & 80,7 & 25.804 & 104,4 \\
\hline 2007 & 302.525 & 42,4 & 369.766 & 78,5 & 29.812 & 15,5 \\
\hline 2008 & 430.259 & 42,2 & 727.961 & 96,9 & 70.068 & 135,0 \\
\hline 2009 & 308.340 & $-28,3$ & 838.125 & 15,1 & 19.509 & $-72,1$ \\
\hline 2010 & 380.328 & 23,3 & 930.179 & 10,9 & 144.553 & 640,9 \\
\hline 2011 & 431.597 & 13,48 & 992.927 & 6,7 & 297.177 & 105,5 \\
\hline 2012 & 542.633 & 25,7 & 1.113 .850 & 12,2 & 174.322 & $-41,3$ \\
\hline
\end{tabular}

Fonte: Brasil (2013b).

Nota: Tabela elaborada pela autora a partir dos dados obtidos na fonte acima indicada.

$\mathrm{Na}$ Tabela 2, apresenta-se um percentual de crescimento acumulado, do período de 2000 a 2012 , de $10.163 \%$, no que se refere aos ingressos; de $66.121 \%$, quanto às matrículas, e de $37.796 \%$, quanto aos concluintes.

A Tabela 3 indica a representatividade quantitativa das matrículas nos cursos de graduação da $\mathrm{EaD}$, em relação ao ensino presencial. 
Tabela 3 - Taxa de crescimento de matrículas em cursos de graduação presenciais e a distância - 2001 a 2012

\begin{tabular}{cccccc}
\hline Ano & $\begin{array}{c}\text { Matrículas } \\
\text { Brasil }\end{array}$ & $\begin{array}{c}\text { Modalidade } \\
\text { presencial }\end{array}$ & $\begin{array}{c}\text { \% de matrículas } \\
\text { na educação } \\
\text { superior }\end{array}$ & $\begin{array}{c}\text { Modalidade a } \\
\text { distância }\end{array}$ & $\begin{array}{c}\text { \% de matrículas } \\
\text { na educação } \\
\text { superior }\end{array}$ \\
\hline 2000 & 2.695 .927 & 2.694 .245 & 99,9 & 1.682 & 00,1 \\
\hline 2012 & 7.037 .688 & 5.923 .838 & 84,2 & 1.113 .850 & 15,8 \\
\hline$\% \Delta$ & 161.048 & 119.870 & 15,71 & 66.121 & 15,8 \\
\hline
\end{tabular}

Fonte: Brasil (2002, 2013c).

Nota: Tabela elaborada pela autora a partir dos dados obtidos nas fontes acima indicadas.

Observa-se que, embora tenha havido acentuado crescimento da $\mathrm{EaD}$, esta representa, no montante total de matrículas da educação superior, 15,8\%. Tal percentual indica crescimento vertiginoso na modalidade em pouco mais de dez anos, mas ainda não atinge os patamares desejáveis para a ampliação da taxa de escolarização líquida e bruta ${ }^{3}$ dos estudantes brasileiros, que, em 20114, representou índices ainda bem inferiores aos atingidos por parcela dos países da América Latina:

[...] Para 2011, a taxa de escolarização bruta é igual a 27,8\%, a taxa de escolarização líquida é igual a $14,6 \%$ e, quando se inclui no cálculo da taxa de escolarização líquida o percentual da população da faixa etária de 18 a 24 anos que concluiu um curso superior, esse valor corresponde a $17,8 \%$ (BRASIL, 2013a, p. 50).

Mormente haja predomínio das matrículas na modalidade presencial, em alguns cursos, tem-se observado a migração significativa de alunos na modalidade presencial para a modalidade a distância. Vale destacar a situação do Curso de Pedagogia, que conta, no Censo de 2012, com 602.998 matrículas, das quais 307.296 são na modalidade presencial e 295.702, na modalidade a distância.

O crescimento significativo em 11 anos não se deu apenas no âmbito da modalidade, mas também, na oferta em instituições privadas. No Censo da Educação Superior, em 2000, não havia oferta em Instituições privadas. As matrículas em instituições privadas são registradas a partir de 2003, com data-base indicada em 30/06/2003;

\footnotetext{
3 "As taxas de escolarização são calculadas utilizando-se exclusivamente dados da PNAD. A taxa de escolarização bruta expressa o percentual da população de 18 a 24 anos que declara frequentar escola. A taxa de escolarização líquida, por sua vez, identifica o percentual da população de 18 a 24 anos que declara cursar graduação [...]." (BRASIL, 2013a, p. 50).

${ }^{4}$ Este índice não abrange as matrículas da modalidade a distância.
} 
e, em 2012, as matrículas nas IES privadas correspondem a $83,7 \%$ do total de matrículas na modalidade. Observou-se, ainda, o crescimento das matrículas nas instituições públicas federais em relação às estaduais e municipais (Tabela 4).

Em 2009, pela primeira vez, o Censo da Educação Superior registrou o número de polos. Os dados apresentaram o predomínio quantitativo da oferta da $\mathrm{EaD}$ na esfera privada, em todos os aspectos: número de polos (74,9\%), ingressos total $(87 \%)$, matrículas $(79,3 \%)$ e concluintes $(85,5 \%)$. Este predomínio se dá na esfera privada, mas, ao contrário do ensino presencial, a oferta é concentrada nas universidades (Tabela 5).

As universidades concentram $63,8 \%$ dos polos de apoio presenciais; $70,6 \%$ dos ingressos total; $70,5 \%$ das matrículas, e $66,2 \%$ dos concluintes (Tabela 6).

As universidades foram responsáveis, ainda, por $84,9 \%$ das vagas ofertadas na $\mathrm{EaD}$, em 2009, do total de 1.561.715 vagas ofertadas no Brasil, para a modalidade a distância (BRASIL, 2010).

Tabela 4 - Taxa de crescimento de matrículas em cursos de graduação a distância, por categoria administrativa - 2001 a 2012

\begin{tabular}{cccccc}
\hline Ano & Total & Federal & Estadual & Municipal & Privada \\
\hline 2000 & 1682 & 300 & 1382 & 0 & 0 \\
\hline 2012 & 1.113 .850 & 102.211 & 64.778 & 14.635 & 932.226 \\
\hline$\% \Delta$ & 66.121 & 33.970 & 4.587 & - & - \\
\hline
\end{tabular}

Fonte: Brasil (2001, 2013c).

Nota: Tabela elaborada pela autora a partir dos dados obtidos nas fontes acima indicadas.

Tabela 5 - Número de Polos, Ingressos Total, Ingressos por Vestibular e Outros Processos Seletivos $\left({ }^{*}\right)$, Matrículas e Concluintes - Brasil-2009

\begin{tabular}{ccccccc}
\hline $\begin{array}{c}\text { Categoria } \\
\text { Administrativa }\end{array}$ & $\begin{array}{c}\text { Número } \\
\text { de Polos }\end{array}$ & $\begin{array}{c}\text { Ingressos } \\
\text { Total }\end{array}$ & $\begin{array}{c}\text { Ingressos por } \\
\text { processos } \\
\text { seletivos }\end{array}$ & $\begin{array}{c}\text { Ingressos } \\
\text { por outras } \\
\text { formas* }\end{array}$ & Matrículas & Concluintes \\
\hline Brasil & 5.904 & 332.469 & 308.340 & 24.129 & 838.125 & 132.269 \\
\hline Pública & 1.478 & 43.186 & 40.284 & 2.902 & 172.696 & 19.073 \\
\hline Federal & 933 & 30.018 & 29.175 & 843 & 86.550 & 1.934 \\
\hline Estadual & 537 & 13.074 & 11.015 & 2.059 & 86.059 & 17.139 \\
\hline Municipal & 8 & 94 & 94 & 0 & 87 & 0 \\
\hline Privada & 4.426 & 289.283 & 268.056 & 21.227 & 665.429 & 113.196 \\
\hline Particular & 3.787 & 239.666 & 224.702 & 14.964 & 527.838 & 85.309 \\
\hline Comun/Confes & 639 & 49.617 & 43.354 & 6.263 & 137.591 & 27.887 \\
\hline
\end{tabular}

Fonte: Brasil (2010). 
Nos dados do Censo de 2012, registra-se perfil similar, havendo discreto crescimento de alguns indicadores, como o número de matrículas e de concluintes (Tabela 7).

Em 2012, o crescimento de polos, ingressos totais, matrículas e concluintes se dá predominantemente em instituições privadas, com a tipologia institucional de universidades (Tabelas 8 e 9).

As instituições privadas são responsáveis, em 2012, por 72,7\% do número de polos; $91,0 \%$ dos ingressos totais; $92,3 \%$ dos ingressos por processos seletivos; $72,0 \%$ dos ingressos por outras formas; $83,7 \%$ das matrículas, e 79,8\% dos concluintes.

Entre as universidades, também são as privadas que congregam o maior percentual em todos os indicadores: $63,8 \%$ do número de polos; $87,8 \%$ dos ingressos totais; $89,6 \%$ dos ingressos por processos seletivos; $67,5 \%$ dos ingressos por outras formas; 79,0\% das matrículas, e 76,4\% dos concluintes (Tabela 9).

Tabela 6 - Número de Polos, Ingressos Total, Ingressos por Vestibular e Outros Processos Seletivos (*), Matrículas e Concluintes nas universidades- Brasil - 2009

\begin{tabular}{cccccccc}
\hline Universidades & $\begin{array}{c}\text { Número } \\
\text { de Polos }\end{array}$ & $\begin{array}{c}\text { Ingresso } \\
\text { Total }\end{array}$ & $\begin{array}{c}\text { Ingressos por } \\
\text { processos } \\
\text { seletivos }\end{array}$ & $\begin{array}{c}\text { Ingressos } \\
\text { por outras } \\
\text { formas* }\end{array}$ & Matrículas & Concluintes \\
\hline Brasil & 3.772 & 235.035 & 217.018 & 18.017 & 591.125 & 87.588 \\
\hline Pública & 1.242 & 39.086 & 36.214 & 2.872 & 159.332 & 18.879 \\
\hline Federal & 697 & 25.918 & 25.105 & 813 & 73.186 & 1.740 \\
\hline Estadual & 537 & 13.074 & 11.015 & 2.059 & 86.059 & 17.139 \\
\hline Municipal & 8 & 94 & 94 & 0 & 87 & 0 \\
\hline Privada & 2.530 & 195.949 & 180.804 & 15.145 & 431.793 & 68.709 \\
\hline Particular & 1.926 & 148.775 & 138.137 & 10.638 & 301.179 & 44.322 \\
\hline Comum/Confes & 604 & 47.174 & 42.667 & 4.507 & 130.614 & 24.387 \\
\hline
\end{tabular}

Fonte: Brasil (2010).

Tabela 7 - Crescimento do número de Polos, Ingressos Total, Ingressos por Vestibular e Outros Processos Seletivos (*), Matrículas e Concluintes, nas Universidades - Brasil -2009 a 2012

\begin{tabular}{ccccccc}
\hline Universidades & $\begin{array}{c}\text { Número de } \\
\text { Polos }\end{array}$ & $\begin{array}{c}\text { Ingresso } \\
\text { Total }\end{array}$ & $\begin{array}{c}\text { Ingressos por } \\
\text { processos } \\
\text { seletivos }\end{array}$ & $\begin{array}{c}\text { Ingressos } \\
\text { por outras } \\
\text { formas* }\end{array}$ & Matrículas & Concluintes \\
\hline 2009 & 3.772 & 235.035 & 217.018 & 18.017 & 591.125 & 87.588 \\
\hline 2012 & 3.669 & 371.695 & 342.354 & 29.341 & 802.645 & 122.258 \\
\hline$\% \Delta$ & $-2,73$ & 58,1 & 57,7 & 62,8 & 35,7 & 39,5 \\
\hline
\end{tabular}

Fonte: Brasil (2010, 2013d).

Nota: Tabela elaborada pela autora a partir dos dados obtidos nas fontes acima indicadas. 
Tabela 8 - Número de Polos, Ingressos Totais, Ingressos por Processos Seletivos, Matrículas e Concluintes, nos Cursos de Graduação a Distância, por Categoria Administrativa das IES - 2012

\begin{tabular}{lcccccc}
\hline $\begin{array}{l}\text { Unidade da Fede- } \\
\text { ração / Categoria } \\
\text { Administrativa }\end{array}$ & $\begin{array}{c}\text { Número } \\
\text { de Polos }\end{array}$ & $\begin{array}{c}\text { Ingressos } \\
\text { Totais }\end{array}$ & $\begin{array}{c}\text { Ingressos por } \\
\text { Processos } \\
\text { Seletivos }\end{array}$ & $\begin{array}{c}\text { Ingressos } \\
\text { por Outras } \\
\text { Formas }\end{array}$ & Matrículas & Concluintes \\
\hline Brasil & 5.432 & 542.633 & 508.268 & 34.365 & 1.113 .850 & 174.322 \\
\hline Pública & 1.480 & 48.527 & 38.911 & 9.616 & 181.624 & 35.152 \\
\hline Federal & 899 & 33.759 & 27.384 & 6.375 & 102.211 & 14.895 \\
\hline Estadual & 363 & 7.792 & 6.082 & 1.710 & 64.778 & 17.885 \\
\hline Municipal & 218 & 6.976 & 5.445 & 1.531 & 14.635 & 2.372 \\
\hline Privada & 3.952 & 494.106 & 469.357 & 24.749 & 932.226 & 139.170 \\
\hline
\end{tabular}

Fonte: Brasil (2013c).

Tabela 9 - Número de Polos, Ingressos Totais, Ingressos por Processos Seletivos, Matrículas e Concluintes, nos Cursos de Graduação, nas Universidades - 2012

\begin{tabular}{lcccccc}
\hline $\begin{array}{l}\text { Unidade da Fede- } \\
\text { ração / Categoria } \\
\text { Administrativa }\end{array}$ & $\begin{array}{c}\text { Número } \\
\text { de Polos }\end{array}$ & $\begin{array}{c}\text { Ingressos } \\
\text { Totais }\end{array}$ & $\begin{array}{c}\text { Ingressos por } \\
\text { Processos } \\
\text { Seletivos }\end{array}$ & $\begin{array}{c}\text { Ingressos por } \\
\text { Outras } \\
\text { Formas }\end{array}$ & Matrículas & Concluintes \\
\hline Total & 3.669 & 371.695 & 342.354 & 29.341 & 802.645 & 122.258 \\
\hline Pública & 1.327 & 45.025 & 35.495 & 9.530 & 167.924 & 28.750 \\
\hline Federal & 746 & 30.257 & 23.968 & 6.289 & 88.511 & 8.493 \\
\hline Estadual & 363 & 7.792 & 6.082 & 1.710 & 64.778 & 17.885 \\
\hline Municipal & 218 & 6.976 & 5.445 & 1.531 & 14.635 & 2.372 \\
\hline Privada & 2.342 & 326.670 & 306.859 & 19.811 & 634.721 & 93.508 \\
\hline
\end{tabular}

Fonte: Brasil (2013d).

A expansão na esfera privada acontece a partir da segunda metade dos anos 2000, quando se desenvolvem os modelos da oferta da modalidade a distância, por meio das teleaulas (aulas satelitárias), bem como ocorrem processos sucessivos de fusões de instituições e a abertura de capital das empresas educacionais de nível superior na bolsa de valores. Atualmente, observa-se grande concentração de instituições mantidas por um mesmo mantenedor e as fusões prosseguem. Os modelos de oferta da graduação quase que totalmente pela internet, com a exceção da realização das avaliações e atividades práticas obrigatórias, estão em franca expansão.

Castro e Cabral Neto (2009) indicam que a formulação de políticas visando à expansão da educação por meio da EaD inicia-se na década de 1990, tendo como principal marco a Conferência de Educação para Todos, em Jomtiem, Tailândia, quando a $\mathrm{EaD}$ foi proposta como estratégia para expandir o atendimento à educação básica. Tais orientações foram incorporadas ao Plano Decenal de Educação para Todos (1993 - 2003), dando origem à estruturação do Sistema Nacional 
de Educação a Distância e à criação da Secretaria de Educação a Distância, em 1994. Mas acentuam:

[...] foi no Planejamento Político-Estratégico (1995-1998), formulado no governo de Fernando Henrique Cardoso, que a EAD passou a ser recomendada em larga escala. O documento traz, em seus princípios básicos, uma posição clara da utilização de novas tecnologias para a melhoria do sistema educacional do país, com destaque especial para o uso da televisão, do computador e da internet [...] (CASTRO; CABRAL NETO, 2009, p. 95).

Os autores observam que, embora não tenham sido concretizadas ações no governo FHC, as bases legais para tal implantação se deram com a publicação da Lei n. ${ }^{\circ}$ 9.394/1996, a Lei de Diretrizes e Bases da Educação vigente; posteriormente, tais ações foram acentuadas no governo de Luís Inácio Lula da Silva (CASTRO; CABRAL NETO, 2009). A expansão efetiva da EaD ocorre a partir dos anos 2005, como se observa nas Tabelas 1 e 2, ainda durante o primeiro mandato de Luís Inácio Lula da Silva e prossegue em crescimento acelerado também no governo de Dilma V. Roussef, agudizando-se a expansão na esfera privada nesta modalidade e a concentração de instituições que ofertam cursos de EaD, a partir de um único mantenedor, com capital aberto na bolsa de valores.

Castro e Cabral Neto (2009, p. 107) admitem a importância do uso da EaD como meio de expansão da educação superior, mas consideram, que a sua qualidade depende essencialmente da mediação entre docentes e estudantes, e da qualidade da proposta pedagógica. Salientam, porém, em concordância com Giolo (2008), que em cursos de formação inicial de professores, a $\mathrm{EaD}$ deve ser apenas uma "[...] atividade complementar à educação presencial" (CASTRO; CABRAL NETO, 2009, p. 107).

A forma de expansão que concentra sua oferta nas ciências humanas e sociais aplicadas, além do predomínio muito acentuado da oferta na esfera privada, não possibilita a democratização do ensino e traz sérias preocupações sobre o desenvolvimento das políticas educacionais, pois, embora a modalidade em si não possa ser tomada como indicador de qualidade, a configuração da oferta em algumas instituições privadas, especialmente as que se limitam ao uso quase exclusivo da web, tem ignorado os referenciais de qualidade (BRASIL, 2007) e as definições preconizadas nas diretrizes curriculares de cada curso, como 
expressam estudos recentes (ROSIN, 2010; MAIA, 2011; SANTANA, 2012; VOLPATO, 2013; SOMMER, 2010).

Evidências concretas sobre estes aspectos poderiam ser obtidas se houvesse a publicização dos resultados da Avaliação e da Regulação da Educação Superior, particularizados por modalidade de ensino.

Seguem informações sobre os cursos de graduação na modalidade a distância no Estado de Mato Grosso do Sul.

\section{A expansão da Modalidade a Distância, na Educação Superior, no Estado de Mato Grosso do Sul, nos anos 2000}

O Estado de Mato Grosso do Sul situa-se em uma área de $357.145 .532 \mathrm{Km}^{2} \mathrm{e}$ uma população de 2.449 .024 habitantes, distribuída em 79 municípios. Conta com baixa densidade demográfica $(6,89)$, já que a maior parte dos municípios possui população inferior a 20 mil habitantes, havendo maior concentração populacional em poucas cidades. $\mathrm{O}$ Estado é conhecido por sua produção agropecuária e desenvolvimento da economia primária. Possui o quarto maior rebanho bovino do país, com 21.553.851 cabeças de gado. Apesar do foco na agropecuária, 86\% da população reside na área urbana (INSTITUTO BRASILEIRO DE GEOGRAFIA E ESTATÍSTICA, 2010a).

A maior parte da população (69\%) encontra-se na faixa etária superior a 18 anos. A população residente dos 18 aos 24 anos é de 306.243 pessoas, enquanto que o quantitativo total de pessoas que frequenta cursos de graduação é de 90.436 , ou seja, menos de $30 \%$ da população na faixa etária considerada para a taxa de escolarização líquida e 19\% da população residente com idade superior a 18 anos. Nos demais níveis do ensino superior, há 10.797 estudantes frequentando cursos de especialização, mestrado e doutorado. Somados todos os níveis da educação superior, são 101.233 pessoas (Tabela 10). Observa-se, na Tabela 11, que há predomínio de pessoas cursando a graduação em instituições privadas (71\%), o que se repete nos cursos de pós-graduação lato sensu e muda apenas nos cursos de pós-graduação stricto sensu, nos quais o predomínio de cursistas está nas instituições públicas (INSTITUTO BRASILEIRO DE GEOGRAFIA E ESTATÍSTICA, 2010a). 
Tabela 10 - Número de pessoas frequentando níveis da educação superior no Estado de Mato Grosso do Sul, em 2010

\begin{tabular}{lc}
\hline \multicolumn{1}{c}{ Caracterização } & $N^{\circ}$ de pessoas \\
\hline Pessoas que frequentavam superior de graduação - Total & 90.436 \\
\hline Pessoas que frequentavam superior de graduação - Pública & 26.313 \\
\hline Pessoas que frequentavam superior de graduação - Particular & 64.123 \\
\hline Pessoas que frequentavam especialização de nível superior - Total & 8.184 \\
\hline Pessoas que frequentavam especialização de nível superior - Pública & 1.581 \\
\hline Pessoas que frequentavam especialização de nível superior - Particular & 6.602 \\
\hline Pessoas que frequentavam mestrado - Total & 2.033 \\
\hline Pessoas que frequentavam mestrado - Pública & 1.075 \\
\hline Pessoas que frequentavam mestrado - Particular & 958 \\
\hline Pessoas que frequentavam doutorado - Total & 580 \\
\hline Pessoas que frequentavam doutorado - Pública & 486 \\
\hline Pessoas que frequentavam doutorado - Particular & 94 \\
\hline
\end{tabular}

Fonte: Instituto Brasileiro de Geografia e Estatística (2010b).

Tabela 11 - Acesso à Internet para Uso Pessoal. PNAD - 2011

\begin{tabular}{lc}
\hline \multicolumn{1}{c}{ Caracterização da população } & \% de acesso \\
\hline $\begin{array}{l}\text { Pessoas de } 10 \text { anos ou mais de idade que utilizaram a internet no período } \\
\text { de referência dos últimos } 3 \text { meses }\end{array}$ & 51,7 \\
\hline $\begin{array}{l}\text { Estudantes de } 10 \text { anos ou mais de idade que utilizaram a internet no } \\
\text { período de referência dos últimos } 3 \text { meses }\end{array}$ & 84,2 \\
\hline $\begin{array}{l}\text { Não Estudantes de } 10 \text { anos ou mais de idade que utilizaram a internet no } \\
\text { período de referência dos últimos } 3 \text { meses }\end{array}$ & 42,1 \\
\hline $\begin{array}{l}\text { Estudantes da rede pública de ensino de } 10 \text { anos ou mais de idade que } \\
\text { utilizaram a internet no período de referência dos últimos 3 meses }\end{array}$ & 80,0 \\
\hline $\begin{array}{l}\text { Estudantes da rede privada de ensino de } 10 \text { anos ou mais de idade que } \\
\text { utilizaram a internet no período de referência dos últimos 3 meses }\end{array}$ & 98,3 \\
\hline $\begin{array}{l}\text { Pessoas de } 10 \text { anos ou mais de idade ocupadas que utilizaram a internet no } \\
\text { período de referência dos últimos } 3 \text { meses }\end{array}$ & 53,1 \\
\hline $\begin{array}{l}\text { Pessoas de } 10 \text { anos ou mais de idade não ocupadas que utilizaram a internet } \\
\text { no período de referência dos últimos } 3 \text { meses }\end{array}$ & 49,7 \\
\hline
\end{tabular}

Fonte: Instituto Brasileiro de Geografia e Estatística (2011).

Além da pequena quantidade de pessoas residentes que frequenta o ensino superior, destaca-se a quantidade da população que nunca frequentou creche ou escola, que soma 141.881 pessoas, ou seja, 6\% da população do Estado (INSTITUTO BRASILEIRO DE GEOGRAFIA E ESTATÍSTICA, 2010a).

Em contraposição, os dados da Pesquisa Nacional de Amostra por Domicílio (PNAD), de 2011, apontam para um bom nível de acesso à internet, especialmente entre os escolarizados e ocupados (Tabela 11). 
Os percentuais razoáveis de acesso, inclusive entre escolares da rede pública, são reflexo das políticas desenvolvidas no estado desde o final dos anos 1990, de adesão ao Programa Nacional de Tecnologia Educacional (Proinfo) ${ }^{5}$, que permitiu a informatização das escolas da rede estadual e em uma parcela significativa de escolas da rede municipal de ensino.

No que toca ao desenvolvimento de cursos de graduação a distância, o estado de Mato Grosso do Sul passa a constar, em 2002, no Censo da Educação Superior, com a oferta do Curso de Pedagogia - Formação do professor das séries iniciais do ensino fundamental, com 280 vagas oferecidas pela Universidade Federal de Mato Grosso do Sul e 189 matriculados. A Tabela 12 apresenta um panorama do desenvolvimento da EaD no estado de Mato Grosso do Sul.

A forma de expansão da $\mathrm{EaD}$ em Mato Grosso do Sul acompanha a expansão nacional, no sentido de que se inicia a oferta em instituição pública federal, com curso de licenciatura e se expande gradativamente, com prevalência de cursos em universidades privadas.

Observa-se, quanto ao número de instituições, que ocorre um decréscimo em 2007, pois de cinco instituições passam a ser quatro; mas, na verdade, ocorre a saída da Universidade para o Desenvolvimento do Estado e da Região do Pantanal (UNIDERP), do consórcio representado pelo Instituto UVB.Br.

A primeira instituição a ofertar a graduação a distância foi a UFMS, credenciada para a oferta do curso de Pedagogia, licenciatura plena, com a habilitação em Magistério dos Anos Iniciais do Ensino Fundamental, e pós-graduação lato sensu, ambos na modalidade a distância, por meio do Parecer CNE/CES 1.114/2001, aprovado em 7 de agosto de 2001. Embora não haja registros no Censo da Educação Superior ${ }^{6}$, a oferta se concentrou em quatro municípios do interior do Estado e se deu mediante demanda das Prefeituras de Coronel Sapucaia, Camapuã, Bela Vista e São Gabriel do Oeste, em função da necessidade de graduar professores regentes que já atuavam nas redes municipais de ensino.

\footnotetext{
${ }^{5}$ O Proinfo foi instituído por meio da Portaria n 522, de 9 de abril de 1997, sendo designado inicialmente como Programa Nacional de Informática na Educação, com a finalidade de disseminar o uso pedagógico das tecnologias de informática e telecomunicações nas escolas públicas de ensino fundamental e médio, sob responsabilidade da então Secretaria de Educação a Distância (SEED) do MEC, em articulação com a secretarias de educação do Distrito Federal, dos Estados e dos Municípios.

${ }^{6}$ Dados obtidos na Coordenadoria de Educação Aberta e a Distância da UFMS.
} 
Tabela 12 - Número de Instituições, cursos de graduação, vagas, candidatos inscritos, ingressos, matrículas e concluintes na modalidade a distância, em instituições sediadas em Mato Grosso do Sul -2000 a 2012

\begin{tabular}{ccccccccc}
\hline Ano & $\begin{array}{c}N^{\circ} \text { de } \\
\text { IES }\end{array}$ & $\begin{array}{c}N^{\circ} \text { de } \\
\text { cursos }\end{array}$ & $\begin{array}{c}\text { Vagas } \\
\text { oferecidas }\end{array}$ & $\begin{array}{c}\text { Candidatos } \\
\text { inscritos }\end{array}$ & $\begin{array}{c}\text { Ingressos } \\
\text { Processo } \\
\text { seletivo }\end{array}$ & $\begin{array}{c}\text { Outras } \\
\text { formas de } \\
\text { ingressos }\end{array}$ & $\begin{array}{c}\text { Matrículas } \\
\text { em 30/06 }\end{array}$ & Concluintes \\
\hline 2000 & 0 & 0 & 0 & 0 & 0 & 0 & 0 & 0 \\
\hline 2001 & 0 & 0 & 0 & 0 & 0 & 0 & 0 & 0 \\
\hline 2002 & 1 & 1 & 280 & 280 & 189 & 0 & 189 & 0 \\
\hline 2003 & 1 & 1 & 80 & 91 & 80 & 0 & 340 & 0 \\
\hline 2004 & 2 & 4 & 660 & 313 & 313 & 0 & 695 & 54 \\
\hline 2005 & 4 & 8 & 3.620 & 3.984 & 2.177 & 0 & 796 & 135 \\
\hline 2006 & 5 & 18 & 23.552 & 12.078 & 6.332 & - & 4.001 & 137 \\
\hline 2007 & 4 & 21 & 72.452 & 21.991 & 14.673 & 209 & 15.573 & 58 \\
\hline 2008 & 4 & 31 & 133.111 & 41.467 & 19.869 & 2.969 & 34.177 & 954 \\
\hline 2009 & $*$ & $*$ & $*$ & $*$ & $9.759 * *$ & 193 & 22.493 & 4.102 \\
\hline 2010 & 4 & $*$ & 231.600 & 82.118 & 31.586 & 129 & 23.782 & 2.600 \\
\hline 2011 & 4 & 41 & 45.410 & 65.332 & 11.159 & 326 & 27.398 & 2.284 \\
\hline 2012 & 6 & 49 & 92.310 & 69.330 & 76.639 & 105 & 140.862 & 11.468 \\
\hline
\end{tabular}

Fonte: Brasil (2013b).

Nota: Tabela elaborada pela autora a partir dos dados obtidos na fonte acima indicada.

* A variação na forma de apresentação dos dados sobre a EaD gera descontinuidade de informações: em 2009, não é possível identificar a quantidade de instituições, cursos, vagas e candidatos inscritos; em 2010, não é possível localizar a quantidade de cursos.

** A partir de 2009, em vez de candidatos ingressos, indicam-se candidatos ingressos por processos seletivos.

A segunda instituição a ofertar graduação a distância em Mato Grosso do Sul foi o Instituto UVB.BR, um consórcio formado por instituições privadas de todo o país ${ }^{7}$. O credenciamento do Instituto ocorreu em 29 de janeiro de 2003, por meio do Parecer CNE/CES n. ${ }^{\circ} 17 / 2003$. O credenciamento por dois anos permitia às instituições parceiras a oferta dos cursos de graduação a distância, bacharelados em Administração de Empresas, Ciências Contábeis, Ciências Econômicas, Secretariado Executivo, Marketing e Turismo.

Entre as instituições parceiras do Instituto UVB.Br, estava a Universidade para o Desenvolvimento do Estado e da Região do Pantanal (Uniderp) ${ }^{8}$, sediada

\footnotetext{
${ }^{7}$ O Consórcio foi formado pelas seguintes instituições: Centro de Ensino Superior de Vila Velha - UVV Espírito Santo; Centro Universitário Monte Serrat - UNIMONTE - São Paulo; Centro Universitário Newton Paiva - NEWTON PAIVA - Minas Gerais; Centro Universitário do Triângulo - UNIT - Minas Gerais; Universidade Anhembi Morumbi - UAM - São Paulo; Universidade da Amazônia - UNAMA - Pará; Universidade Potiguar - UNP - Rio Grande do Norte; Universidade Veiga de Almeida - UVA - Rio de Janeiro; Universidade para o Desenvolvimento do Estado e da Região do Pantanal - Uniderp - Mato Grosso do Sul; Universidade do Sul de Santa Catarina - UNISUL - Santa Catarina.

${ }^{8}$ Com a publicação da Portaria SESu n. ${ }^{\circ} 879$, em 18 de novembro de 2008, a Uniderp passou a ser denominada Universidade Anhanguera-Uniderp.
} 
em Mato Grosso do Sul, que possuía credenciamento para a oferta de cursos de pós-graduação lato sensu, desde 2002, por meio do Parecer CNE/CES n. ${ }^{\circ}$ 248/2002, aprovado em 7 de agosto de 2002. Esta instituição, posteriormente, foi credenciada em 2005 para a oferta de cursos de graduação a distância, sendo incorporada pela Anhanguera Educacional em $2008^{9}$.

Em 2005, a Universidade Católica Dom Bosco (UCDB), após o credenciamento, por meio do Parecer CNE/CES n. ${ }^{\circ}$ 9/2005, aprovado em 2 de fevereiro de 2005, começou a ofertar cursos de graduação a distância: Ciências Contábeis, Administração de Agronegócios e Administração Pública.

Em 2006, o Centro Universitário da Grande Dourados (UNIGRAN) ${ }^{10}$ também passou a oferecer cursos de graduação a distância: Pedagogia, Formação de Professor - Letras, Marketing e Publicidade Mercadológica, Ciências Contábeis, Administração, Gestão de Imóveis e Agropecuária.

Além das instituições que constam no Censo da Educação Superior, outras duas - a Universidade Federal da Grande Dourados (UFGD) e a Universidade Estadual de Mato Grosso do Sul (UEMS) - também ofertam cursos de graduação a distância. Esta oferta se deu a partir do credenciamento experimental para IES públicas, estabelecido inicialmente para a UEMS, por meio da Portaria MEC n..$^{\circ} 1.050$, de 22 de Agosto de 2008, exclusivamente para a oferta de cursos superiores na modalidade a distância aprovados no âmbito do "Sistema Universidade Aberta do Brasil-UAB"; posteriormente, houve credenciamento para ambas as instituições, por meio da Portaria Normativa MEC n. ${ }^{\circ} 1.369$, de 7 de dezembro de 2010.

A UFGD aderiu ao Sistema Universidade Aberta do Brasil (UAB) em 2009 e passou a ofertar: Bacharelado em Administração Pública, Licenciatura em Computação e Licenciatura em Pedagogia. Em 2012, acrescentou-se a oferta de Licenciatura em Física e Licenciatura em Letras-Libras. A UEMS oferta o curso de Administração Pública.

O modelo de $\mathrm{EaD}$ oferecido nas instituições é diferente e tem variado ao longo do tempo. A UFMS iniciou seus cursos apenas com materiais impressos e aulas

\footnotetext{
${ }^{9}$ A mudança de mantença se deu por meio da Portaria SESu n. ${ }^{\circ} 1.620 / 09$, publicada no Diário Oficial da União, em 16 de novembro de 2009.

${ }^{10} \mathrm{~A}$ instituição foi credenciada para a oferta de cursos de pós-graduação a distância, por meio do Parecer CNE/CES n. ${ }^{\circ}$ 43/2005, aprovado em 23 de fevereiro de 2005, e credenciada para a oferta de cursos de graduação por meio da Portaria MEC n. ${ }^{\circ}$ 4.070, de 29 de novembro de 2005.
} 
presenciais. A partir da adesão ao Sistema Universidade Aberta do Brasil (UAB), passou a contar com o Ambiente Virtual de Aprendizagem, tutoria presencial e a distância, e mais recentemente, com webaulas, webconferências e videoaulas gravadas.

A Uniderp iniciou seus cursos com o modelo de aulas satelitárias com interatividade síncrona, acompanhado de atividades presenciais duas vezes na semana, com tutorial presencial, material impresso, ambiente virtual de aprendizagem e tutoria a distância. Mais recentemente, está oferecendo também um modelo exclusivamente via web - excetuadas as avaliações presenciais - que conta com o ambiente virtual de aprendizagem e a tutoria a distância.

A UCDB e a Unigran oferecem o modelo que conta com o ambiente virtual de aprendizagem, tutoria a distância e avaliações e atividades práticas presenciais.

A UFGD e a UEMS ofertam os cursos por meio de ambiente virtual de aprendizagem, aulas presenciais realizadas por tutores e webconferências.

Quanto ao número de cursos, o crescimento é gradual e demonstra, de um lado, a cautela das instituições, que ofertam poucos cursos, mas, em contrapartida, ampliam a quantidade de vagas ofertadas. Observa-se a desigualdade entre as vagas oferecidas, os candidatos inscritos, os ingressos, os matriculados e os concluintes, com indicadores claros de ociosidade de vagas, com exceção do ano de 2003, no qual a oferta de vagas é equivalente à quantidade de ingressantes (Tabela 13).

Os dados da Tabela 13 indicam o crescimento gradativo das vagas até 2010, acompanhado pelo crescimento também das vagas ociosas até 2010, pois em 2011 ocorre a redução significativa das vagas, possivelmente como decorrência dos processos de regulação do Estado e também da clareza da ociosidade muito representativa, especialmente a partir de 2006. Em 2012, observa-se nova ampliação na oferta de vagas, inscritos e ingressos, e redução da ociosidade de vagas.

Levando-se em consideração o período em que, por meio dos dados do Censo, podem-se identificar aspectos da oferta, por instituição - 2000 a 2008 - e depois, novamente a partir de 2010, observa-se que a ociosidade de vagas ocorre com maior ênfase nas IES privadas, pois são estas que oferecem maior número de vagas. No caso de Mato Grosso do Sul, a Uniderp, a Unigran e a UCDB, em ordem decrescente, apresentam maior ociosidade de vagas. 
Tabela 13 - Relação entre vagas ofertadas, candidatos inscritos, candidatos ingressantes e ingressos

\begin{tabular}{cccccc}
\hline Ano & Vagas oferecidas & $\begin{array}{c}\text { Candidatos } \\
\text { inscritos }\end{array}$ & $\begin{array}{c}\text { Candidatos } \\
\text { Ingressos }\end{array}$ & $\begin{array}{c}\text { Diferença entre } \\
\text { vagas ofertas e } \\
\text { inscritos }\end{array}$ & $\begin{array}{c}\text { Diferença entre } \\
\text { vagas ofertadas } \\
\text { e ingressos }\end{array}$ \\
\hline 2000 & 0 & 0 & 0 & 0 & 0 \\
\hline 2001 & 0 & 0 & 0 & 0 & 0 \\
\hline 2002 & 280 & 280 & 189 & 0 & 91 \\
\hline 2003 & 80 & 91 & 80 & -11 & 0 \\
\hline 2004 & 660 & 313 & 313 & 347 & 347 \\
\hline 2005 & 3.620 & 3.984 & 2.177 & -364 & 1.443 \\
\hline 2006 & 23.552 & 12.078 & 6.332 & 11.474 & 17.220 \\
\hline 2007 & 72.452 & 21.991 & 14.673 & 50.461 & 57.779 \\
\hline 2008 & 133.111 & 41.467 & 19.869 & 91.644 & 113.242 \\
\hline 2009 & $*$ & $*$ & $9.759 * *$ & - & - \\
\hline 2010 & 231.600 & 82.118 & 31.586 & 149.482 & 200.014 \\
\hline 2011 & 45.410 & 65.332 & 11.159 & -19.922 & 34.251 \\
\hline 2012 & 92.310 & 69.330 & 76.744 & 15.566 & 22.980 \\
\hline
\end{tabular}

Fonte: Brasil (2013b).

Nota: Tabela elaborada pela autora a partir dos dados obtidos na fonte acima indicada.

* A variação na forma de apresentação dos dados sobre a EaD gera descontinuidade de informações: em 2009, não é possível identificar a quantidade de instituições, cursos, vagas e candidatos inscritos; em 2010, não é possível localizar a quantidade de cursos.

** A partir de 2009, em vez de candidatos ingressos, indicam-se candidatos ingressos por processos seletivos.

No ano de 2010, por exemplo, quando ocorre a maior oferta de vagas e também de ociosidade, a Uniderp ofertou 201.600 vagas, contou com 72.986 inscritos, mas apenas 27.336 ingressantes, ou seja, apenas $13,5 \%$ das vagas oferecidas foram ocupadas. No caso da Unigran, neste mesmo ano, apenas $11 \%$ das vagas oferecidas foram preenchidas. Já a UCDB, instituição privada confessional, apresentou o melhor aproveitamento, com 50,9\% de vagas preenchidas, mas é a IES privada que menos oferta vagas, 2000, contra 201.600 da Uniderp e 28.000 da Unigran (Tabela 14).

Embora apresente alta ociosidade de vagas, a Uniderp foi responsável, em 2010, por $80,8 \%$ dos ingressantes da Região Centro-Oeste e $86,2 \%$ dos ingressantes do Estado de Mato Grosso do Sul.

A Tabela 12 expõe a quantidade de ingressos e concluintes, mas não é possível estabelecer uma relação direta entre estes indicadores em razão da variação de tempo para integralização dos cursos e do próprio fluxo acadêmico, com transferências e trancamentos. 
Tabela 14 - Número de vagas, candidatos inscritos e ingressos na Região Centro-Oeste, no Estado de Mato Grosso do Sul e nas IES sediadas em Mato Grosso do Sul - 2010

\begin{tabular}{|c|c|c|c|c|c|c|}
\hline \multirow[b]{2}{*}{$\begin{array}{l}\text { Região / Estado / } \\
\text { Instituições }\end{array}$} & \multirow[b]{2}{*}{$\begin{array}{l}\text { Vagas } \\
\text { Oferecidas }\end{array}$} & \multirow[b]{2}{*}{$\begin{array}{l}\text { Candidatos } \\
\text { Inscritos }\end{array}$} & \multirow[b]{2}{*}{$\begin{array}{c}\text { Relação Candi- } \\
\text { datos Inscritos/ } \\
\text { Vagas } \\
\text { Oferecidas }\end{array}$} & \multicolumn{3}{|c|}{ Ingressos } \\
\hline & & & & $\begin{array}{l}\text { Processo } \\
\text { Seletivo } \\
\text { e Outras } \\
\text { Formas }\end{array}$ & $\begin{array}{l}\text { Processo } \\
\text { Seletivo }\end{array}$ & $\begin{array}{l}\text { Outras } \\
\text { Formas }\end{array}$ \\
\hline Centro-Oeste & 238.427 & 91.556 & 0,4 & 33.807 & 33.571 & 236 \\
\hline Mato Grosso do Sul & 231.600 & 82.118 & 1,5 & 31.715 & 31586 & 129 \\
\hline $\begin{array}{l}\text { Universidade Anhan- } \\
\text { guera - Uniderp }\end{array}$ & 201.600 & 72.986 & 0,4 & 27.336 & 27.336 & 0 \\
\hline $\begin{array}{c}\text { Universidade Católi- } \\
\text { ca Dom Bosco }\end{array}$ & 2.000 & 1.623 & 0,8 & 1.018 & 889 & 129 \\
\hline $\begin{array}{c}\text { Universidade Federal } \\
\text { de Mato Grosso do } \\
\text { Sul }\end{array}$ & 0 & 0 & 0 & 261 & 261 & 0 \\
\hline $\begin{array}{c}\text { Centro } \\
\text { Universitário da } \\
\text { Grande } \\
\text { Dourados } \\
\end{array}$ & 28.000 & 7.509 & 0,3 & 3.100 & 3.100 & 0 \\
\hline
\end{tabular}

Fonte: Brasil (2011).

Nota: Tabela elaborada pela autora a partir dos dados obtidos na fonte acima indicada.

No que toca às áreas de conhecimento dos cursos oferecidos ${ }^{11}$, estas se concentram nas ciências humanas e sociais, e ciências sociais aplicadas. Apenas a Uniderp oferece dois cursos na área da saúde e bem-estar social: Serviço Social e Enfermagem. A Unigran oferece um curso na área de Ciências, Matemática e Computação, e outro na área da Agricultura e Veterinária (Quadro 1).

A ênfase na oferta de cursos nas áreas de Ciências Humanas e Ciências Sociais Aplicadas permite uma série de hipóteses: são áreas nas quais os cursos, em geral, não requerem laboratórios, portanto são cursos de baixo custo; o curso mais frequente nas Ciências Sociais Aplicadas - Administração - tem facilidades operacionais definidas em suas Diretrizes Curriculares ${ }^{12}$, que não determinam a carga horária mínima para o Estágio Obrigatório e indicam a possibilidade de sua realização na forma de laboratórios de gestão realizados na própria instituição de ensino, como também definem o Trabalho de Conclusão de Curso como atividade opcional; há sérias restrições ainda no meio social e nas associações de categorias de classe em relação aos cursos na modalidade a distância, como

\footnotetext{
${ }^{11}$ Os dados do Quadro 1 restringem-se ao período de 2000 a 2008, pois a forma de exposição de informações a partir de 2009 inviabiliza a identificação da oferta de cursos, por área, por instituição de ensino e por região.

${ }^{12}$ Instituídas por meio da Resolução CNE/CES n. 1, de 2 de fevereiro de 2004.
} 
no caso do curso de Serviço Social, em que o Conselho Federal de Serviço Social (CFSS) e os Conselhos Regionais (CRESS) atuam fortemente para inibir assistentes sociais a oferecerem supervisão de estágio aos acadêmicos de cursos da modalidade a distância, impossibilitando a integralização dos currículos e ignorando a legislação vigente.

Para além das hipóteses, o fato patente é de que a expansão dos cursos em EaD em Mato Grosso do Sul, à semelhança da situação nacional, não ocorre em todas as áreas de conhecimento; portanto, não há um processo igualitário de oferta, pois cidadãos moradores de determinadas cidades e regiões não têm acesso a cursos de graduação em todas as áreas de conhecimento. Tal situação vem gerando a migração dos jovens que buscam determinadas áreas de atividade para outros municípios, em geral sem retorno, o que se evidencia nas estatísticas da diminuição demográfica em alguns municípios do interior do Estado e na inexistência de profissionais habilitados nas engenharias, na área da saúde e bem-estar social, bem como nas áreas da agricultura e veterinária, áreas bastante importantes para um Estado que tem, como principal atividade econômica, a agropecuária.

Os cursos indicados no Quadro 1 nem sempre são ofertados em todos os polos cadastrados como polos de apoio presencial. As instituições solicitam a abertura de polos de apoio ao ensino, que passam por avaliação do Ministério da Educação, e mediante cada edital de processo seletivo para cursos de graduação, a oferta pode se dar nos polos em que houve efetivamente a demanda.

Entre as instituições sediadas em Mato Grosso do Sul, a instituição que possui maior número de polos é a Universidade Anhanguera-Uniderp, com 455 polos, distribuídos em 24 Estados e no Distrito Federal: Alagoas-AL; Amapá-AP; Amazonas-AM; Bahia-BA; Ceará-CE; Distrito Federal - DF; Espírito Santo-ES; Goiás-GO; Maranhão-MA; Mato Grosso-MT; Mato Grosso do Sul-MS; Minas Gerais-MG; Pará-PA; Paraíba-PB; Paraná-PR; Pernambuco-PE; Piauí-PI; Rio de Janeiro-RJ; Rio Grande do Norte-RN; Rio Grande do Sul-RS; Rondônia-RO; Santa Catarina-SC; São Paulo-SP; Sergipe-SE; Tocantins-TO (BRASIL, 2009a).

A UNIGRAN conta com 26 polos credenciados, distribuídos em nove Estados e no Distrito Federal: Espírito Santo-ES; Maranhão-MA; Mato Grosso-MT; Mato Grosso do Sul-MS; Paraíba-PB; Paraná-PR; Santa Catarina-SC; São Paulo-SP; Tocantins-TO (BRASIL, 2009a).

A UFMS atua em 18 polos, distribuídos nos Estados de Mato Grosso do Sul-MS; Paraná-PR e São Paulo-SP, e a UCDB conta com 15 polos credenciados nos 
Quadro 1 - Área geral, programas e cursos oferecidos nas Instituições de Educação Superior sediadas em Mato Grosso do Sul, na modalidade a distância

\begin{tabular}{|c|c|c|c|}
\hline IES & Área Geral & Programas & Cursos \\
\hline \multirow{10}{*}{$\begin{array}{c}\text { Uniderp } \\
\text { Anhanguera }\end{array}$} & \multirow[b]{2}{*}{ Educação } & Ciências da Educação & Pedagogia \\
\hline & & $\begin{array}{l}\text { Formação de professor de } \\
\text { matérias específicas }\end{array}$ & $\begin{array}{l}\text { Formação de professor } \\
\text { de Língua/Literatura } \\
\text { Vernácula e Língua Es- } \\
\text { trangeira Moderna }\end{array}$ \\
\hline & \multirow{6}{*}{$\begin{array}{l}\text { Ciências Sociais, } \\
\text { Negócios e Direito }\end{array}$} & Contabilidade e Tributação & Ciências contábeis \\
\hline & & \multirow{4}{*}{$\begin{array}{l}\text { Gerenciamento e } \\
\text { Administração }\end{array}$} & Administração \\
\hline & & & Administração Hospitalar \\
\hline & & & $\begin{array}{l}\text { Gestão de Pessoal/ } \\
\text { Recursos Humanos }\end{array}$ \\
\hline & & & Gestão Logística \\
\hline & & Marketing e Publicidade & Mercadologia (marketing) \\
\hline & \multirow[t]{2}{*}{$\begin{array}{c}\text { Saúde e } \\
\text { Bem-Estar Social }\end{array}$} & $\begin{array}{c}\text { Enfermagem e Atenção } \\
\text { Primária (assistência básica) }\end{array}$ & Enfermagem \\
\hline & & Serviço Social e Orientação & Serviço Social \\
\hline \multirow{6}{*}{$\begin{array}{l}\text { Universidade } \\
\text { Católica Dom } \\
\text { Bosco }\end{array}$} & \multirow{5}{*}{$\begin{array}{l}\text { Ciências Sociais, } \\
\text { Negócios e Direito }\end{array}$} & Contabilidade e Tributação & Ciências Contábeis \\
\hline & & \multirow{4}{*}{$\begin{array}{l}\text { Gerenciamento e } \\
\text { Administração }\end{array}$} & $\begin{array}{l}\text { Administração de Agro- } \\
\text { negócios }\end{array}$ \\
\hline & & & Administração Pública \\
\hline & & & Gestão Financeira \\
\hline & & & $\begin{array}{c}\text { Vendas e Varejos } \\
\text { Negócios Imobiliários }\end{array}$ \\
\hline & Serviços & $\begin{array}{l}\text { Proteção Ambiental } \\
\text { (cursos gerais) }\end{array}$ & Gestão Ambiental \\
\hline \multirow{3}{*}{$\begin{array}{l}\text { Universidade } \\
\text { Federal de Mato } \\
\text { Grosso do Sul }\end{array}$} & \multirow{2}{*}{ Educação } & Ciências da Educação & Pedagogia \\
\hline & & $\begin{array}{c}\text { Formação de professor de } \\
\text { matérias específicas }\end{array}$ & $\begin{array}{c}\text { Formação de professor } \\
\text { de Biologia }\end{array}$ \\
\hline & $\begin{array}{l}\text { Ciências Sociais, } \\
\text { Negócios e Direito }\end{array}$ & $\begin{array}{l}\text { Gerenciamento e } \\
\text { Administração }\end{array}$ & Administração \\
\hline \multirow{9}{*}{$\begin{array}{l}\text { Centro } \\
\text { Universitário da } \\
\text { Grande } \\
\text { Dourados }\end{array}$} & \multirow[b]{2}{*}{ Educação } & Ciências da Educação & Pedagogia \\
\hline & & $\begin{array}{l}\text { Formação de professores } \\
\text { de matérias específicas }\end{array}$ & $\begin{array}{c}\text { Formação de professores } \\
\text { de Letras }\end{array}$ \\
\hline & $\begin{array}{l}\text { Humanidades e } \\
\text { Artes }\end{array}$ & Religião e Teologia & Teologia \\
\hline & \multirow{4}{*}{$\begin{array}{l}\text { Ciências Sociais, } \\
\text { Negócios e Direito }\end{array}$} & Contabilidade e Tributação & Ciências Contábeis \\
\hline & & $\begin{array}{l}\text { Gerenciamento e } \\
\text { Administração }\end{array}$ & Administração \\
\hline & & Marketing e Publicidade & $\begin{array}{l}\text { Publicidade e } \\
\text { Propaganda }\end{array}$ \\
\hline & & $\begin{array}{l}\text { Vendas em atacado e } \\
\text { varejo }\end{array}$ & Negócios Imobiliários \\
\hline & $\begin{array}{l}\text { Ciências, Matemáti- } \\
\text { ca e Computação }\end{array}$ & $\begin{array}{l}\text { Processamento da } \\
\text { Informação }\end{array}$ & $\begin{array}{c}\text { Análise e Desenvolvimen- } \\
\text { to de Sistemas }\end{array}$ \\
\hline & $\begin{array}{l}\text { Agricultura e } \\
\text { Veterinária }\end{array}$ & Produção Agrícola & Agroindústria \\
\hline
\end{tabular}

Fonte: Brasil (2009b).

Nota: Quadro elaborado pela autora a partir dos dados obtidos na fonte acima indicada. 
Estados: Bahia-BA; Goiás-GO; Mato Grosso-MT; Mato Grosso do Sul-MS; Minas Gerais-MG; Pará-PA; Pernambuco-PE; São Paulo-SP e no Distrito Federal-DF (BRASIL, 2009a).

No que toca à cobertura das cidades de Mato Grosso do Sul, as IES sediadas no Estado cobrem todas as meso e microrregiões ${ }^{13}$, mas não há oferta em todos os municípios (Quadro 2).

Embora 37 municípios não disponham de cobertura da modalidade a distância, vários são atendidos por instituições sediadas em outros Estados ou por campus das universidades ou instituições que ofertam cursos presenciais. Outro fator é a proximidade de algumas cidades com centros maiores que são polos de IES, como é o caso de Terenos e Sidrolândia, cidades muito próximas de Campo Grande, capital do Estado.

Nos sites das instituições e no Cadastro da Educação Superior (Cadastro e-MEC) $)^{14}$, constam outros cursos de graduação a distância, que passaram a ser oferecidos a partir de 2009, sendo possível observar o crescimento da oferta de cursos superiores de tecnologia nas instituições privadas; entretanto, como não há congruência entre os dados disponíveis nas várias bases, torna-se inviável identificar e analisar as inserções a partir de 2009.

A oferta de cursos de graduação na modalidade a distância por parte de instituições não sediadas em Mato Grosso do Sul, mas que dispõem de polos de apoio ao ensino no Estado, é também bastante significativa. São muitas as instituições: Centro Universitário Claretiano - CEUCLAR; Centro Universitário de Maringá - CEUMAR-CESUMAR; Centro Universitário do Instituto de Ensino Superior - COC; Centro Universitário Internacional - UNINTER; Centro Universitário Leonardo da Vinci - UNIASSELVI; Faculdade AIEC - AIEC/FAAB; Universidade Anhembi Morumbi - UAM; Universidade de Santo Amaro - UNISA; Universidade do Sul de Santa Catarina; Universidade Estácio de Sá - UNESA; Universidade Federal do Rio Grande do Sul - UFRGS; Universidade Luterana do Brasil ULBRA; Universidade Metodista de São Paulo - UMESP; Universidade do Norte

\footnotetext{
${ }^{13} \mathrm{O}$ Estado de Mato Grosso do Sul possui quatro mesorregiões: Pantanais sul-mato-grossenses, CentroNorte de MS, Leste de MS e Sudoeste de MS, e 11 microrregiões: Baixo Pantanal, Aquidauana, Alto Taquari, Campo Grande, Cassilândia, Paranaíba, Três Lagoas, Nova Andradina, Iguatemi, Dourados e Bodoquena, conforme organização do IBGE.

${ }^{14} \mathrm{O}$ Cadastro da Educação Superior (Cadastro e-MEC) é uma ferramenta que permite ao público a consulta de dados sobre instituições de educação superior, públicas e privadas, e seus cursos. O Cadastro informa dados como a situação de regulação das instituições e dos cursos por estas oferecidos, endereços de oferta e indicadores de qualidade obtidos nas avaliações do MEC.
} 
Quadro 2 - Municípios de Mato Grosso do Sul nos quais funcionam polos de apoio ao ensino, por instituição sediada no estado

\begin{tabular}{|c|c|}
\hline IES & Municípios dos polos de apoio ao ensino em Mato Grosso do Sul \\
\hline $\begin{array}{l}\text { Universidade UNIDERP } \\
\text { Anhanguera }\end{array}$ & $\begin{array}{l}\text { Alcinópolis, Aparecida do Taboado, Aquidauana, Bataguassu, Bela } \\
\text { Vista, Bela Vista, Bonito, Camapuã, Campo Grande, Cassilândia, } \\
\text { Corguinho, Coronel Sapucaia, Corumbá, Dourados, Eldorado, } \\
\text { Glória de Dourados Iguatemi, Itaquiraí, Ivinhema, Jardim, Miranda, } \\
\text { Naviraí, Nioaque, Nova Alvorada do Sul, Nova Andradina, Novo } \\
\text { Horizonte do Sul, Paranhos, Pedro Gomes, Ponta Porã, Ribas do } \\
\text { Rio Pardo, Rio Verde de Mato Grosso, São Gabriel D'Oeste, Sete } \\
\text { Quedas, Sidrolândia, Três Lagoas. }\end{array}$ \\
\hline $\begin{array}{l}\text { Universidade Federal de } \\
\text { Mato Grosso Do Sul }\end{array}$ & $\begin{array}{l}\text { Água Clara, Bela Vista, Camapuã, Campo Grande, Chapadão do } \\
\text { Sul, Costa Rica, Jardim, Paranhos, Porto Murtinho, Rio Brilhante. }\end{array}$ \\
\hline $\begin{array}{l}\text { Universidade Católica Dom } \\
\text { Bosco }\end{array}$ & Campo Grande, Corumbá, São Gabriel d'Oeste e Sonora. \\
\hline $\begin{array}{l}\text { Centro Universitário da } \\
\text { Grande Dourados }\end{array}$ & $\begin{array}{l}\text { Amambaí, Aral Moreira, Bonito, Campo Grande, Chapadão do } \\
\text { Sul, Corumbá, Costa Rica, Dourados, Jardim, Jateí, Naviraí, Nova } \\
\text { Andradina, Ponta Porã, Três Lagoas. }\end{array}$ \\
\hline
\end{tabular}

Fonte: Brasil (2009a).

Nota: Quadro elaborado pela autora a partir dos dados obtidos na fonte acima indicada.

do Paraná - UNOPAR; Universidade Paulista - UNIP; Universidade Salvador - UNIFACS; Universidade do Sul de Santa Catarina - UNISUL; Universidade de Tecnologia e Ciências - FCT Salvador, e Universidade Metropolitana de Santos - UNIMES (BRASIL, 2013e).

Não é possível, no Censo da Educação Superior e nas bases oficiais de consulta de dados, mapear a quantidade de vagas ofertadas por estas instituições no Estado, mas a consulta no Cadastro da Educação Superior, na base do e-MEC, por instituição de ensino, permite a identificação dos cursos oferecidos e os municípios dos polos de apoio ao ensino. A consulta realizada em 2012 aponta para uma quantidade significativa de cursos oferecidos em quase todos os municípios do Estado de Mato Grosso do Sul, praticamente nas mesmas áreas oferecidas pelas instituições sediadas no Estado.

A título de exemplificação, o Centro Universitário Claretiano - CEUCLAR, sediado em Batatais-SP, oferta em um único polo de apoio ao ensino, no município de Campo Grande-MS, os seguintes cursos: Administração, Agronegócios, Análise e Desenvolvimento de Sistemas, Artes, Biologia, Ciências Contábeis, Ciências da Religião, Ciências Sociais, Comércio Exterior, Computação, Comunicação Institucional, Design Gráfico, Educação Física, Engenharia da Produção, Estética, Filosofia, Geografia, Gestão Ambiental, Gestão da Qualidade, Gestão da Tecnologia da Informação, Gestão de Recursos Humanos, Gestão de Segurança Privada, 
Gestão de Turismo, Gestão Financeira, Gestão Pública, História, Hotelaria, Letras, Marketing, Matemática, Negócios Imobiliários, Pedagogia, Processos Gerenciais, Produção Multimídia, Programa Especial de Formação Pedagógica de Docentes, Química, Segurança no Trabalho, Serviço Social, Sistemas para Internet e Teologia (BRASIL, 2013e).

No caso de outras instituições, a oferta se concentra em poucos cursos, mas distribuída em vários municípios.

O impacto da oferta das instituições não sediadas em Mato Grosso do Sul não pode ser analisado sem a percepção clara da quantidade de alunos matriculados, mas, de toda a sorte, a existência de tantas instituições aponta para um processo de interiorização, com a possibilidade concreta de acesso a cursos de graduação em quase todos os municípios do Estado de Mato Grosso do Sul, mesmo que concentrados em algumas áreas de conhecimento.

Entre as IES privadas sediadas no Estado de Mato Grosso do Sul, é inegável o impacto da Universidade Anhanguera-Uniderp, dado o seu gigantismo em todos os indicadores analisados. Torna-se, deste modo, essencial pontuar as mudanças ocorridas na instituição a partir da alteração de mantença do Cesup para a Anhanguera Educacional Participações S.A. e, mais recentemente, a indicação da fusão entre esta empresa e a Kroton Educacional S.A.

O anúncio oficial da fusão entre a Kroton Educacional S.A. e a Anhanguera Educacional Participações S.A., em 22 de abril de 2013, cimenta a presença de um oligopólio com destaque no setor corporativo mundial, já que, juntas, as companhias serão responsáveis pelo maior volume de recursos de uma companhia educacional no mundo. O presidente da Kroton Educacional, Rodrigo Galindo, salienta o peso econômico das duas empresas juntas, em âmbito mundial: "Nós já éramos a primeira e a terceira maiores companhias do mundo em valor de mercado e juntas somos mais que o dobro que a segunda maior companhia de educação do mundo, a New Oriental. [...]" (G1, 2013). O Gráfico 1 registra o potencial econômico das empresas em questão.

Em relação ao impacto para a organização de instituições, as duas companhias, conforme registra comunicado oficial da Kroton, serão responsáveis por um milhão de alunos, distribuídos em 835 cidades em todos os Estados brasileiros, em 123 campi de ensino presencial, 647 polos de ensino a distância e 810 escolas associadas na educação básica, empregando cerca de 32 mil profissionais. 
Gráfico 1 - Valor de mercado de empresas de educação de capital aberto no mundo, em milhões de dólares

$$
\text { Market Cap (US\$ milhões) }
$$

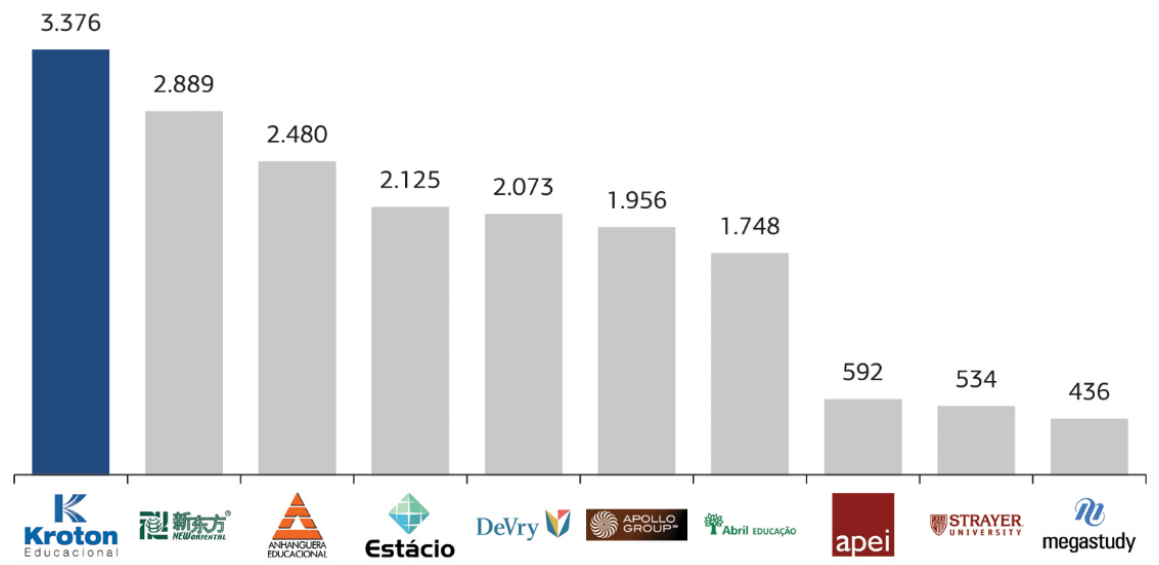

Fonte: BLOOMBERG, de 19 de abril (Foto: Reprodução/Kroton), gráfico reproduzido no G1 Economia $(G 1,2013)$.

Atualmente, no âmbito da Educação a Distância, a Anhanguera Educacional conta com aproximadamente 490 mil alunos, em 70 campi e mais de 500 unidades de educação a distância, incluindo a Rede LFG, especialista na preparação e na qualificação de profissionais para atuar com excelência no setor público. A Kroton atende a mais de 500 mil alunos no ensino superior, nas modalidades de ensino presencial e a distância, por meio dos 53 campi localizados em dez Estados do Brasil e em 39 municípios, além de 447 polos ativos de graduação de EAD. Na educação básica, são 289 mil alunos, distribuídos em 810 escolas associadas em todos os Estados do Brasil (KROTON EDUCACIONAL; ANHANGUERA EDUCACIONAL PARTICIPAÇÕES, 2013).

O acordo proposto em abril foi aprovado recentemente pelo Conselho Administrativo de Defesa Econômica (CADE). O oligopólio gerado por esta fusão tem aspectos especialmente preocupantes no âmbito da padronização e do empobrecimento dos currículos, caso sejam mantidas as políticas desenvolvidas pela Anhanguera Educacional Participações S.A. A empresa trabalha com o programa de Livro-texto (PLT), que consiste na compra dos direitos autorais de editoras e autores para oferta a baixo custo de obras que são definidas, em nível nacional, nas instituições de ensino da rede, sendo que o preço dos livros-texto já está diluído nas mensalidades. Tal ação, além de retirar a autonomia didático-pedagógica dos docentes, padroniza e limita a gama de conhecimentos no processo de formação. Outro aspecto é a 
retirada de todas as atividades de formação não previstas nas Diretrizes Curriculares Nacionais e a oferta de cursos com tempo muito reduzido para a integralização do currículo, como é o caso de licenciaturas, que estão sendo ofertadas com as 2.800 horas mínimas definidas na legislação e em três anos de duração.

No próximo item, são traçadas considerações finais sobre o processo de expansão dos cursos de graduação, na modalidade a distância, em Mato Grosso do Sul.

\section{Considerações finais}

Os dados obtidos nesta pesquisa permitem concluir que a expansão dos cursos de graduação a distância no Estado de Mato Grosso do Sul não difere substantivamente da expansão em âmbito nacional, pois, da mesma forma que o ocorrido em âmbito nacional, a oferta dos cursos de graduação em Mato Grosso do Sul inicia-se com curso de licenciatura, em instituição pública federal. Nos dados mais recentes do Censo da Educação Superior, percebe-se o predomínio da oferta na esfera privada, em instituições universitárias, acompanhado pela ociosidade de vagas. Há preponderância da oferta de cursos nas áreas das Ciências Humanas e Sociais Aplicadas.

No que toca à interiorização, a oferta de cursos se dá em todas as microrregiões do Estado de Mato Grosso do Sul, mas, de forma mais significativa, por instituições privadas. A UFMS, única IES pública indicada no Censo da Educação Superior, até 2011, contempla nove das microrregiões do Estado, mas com a oferta em poucos municípios, praticamente um ou dois por microrregião. As demais IES públicas que passam a ofertar cursos em 2009 utilizam os mesmos polos de apoio ao ensino que a UFMS, portanto, com a mesma cobertura. A privatização na oferta da EaD no Estado de Mato Grosso do Sul vem crescendo significativamente a partir de 2006, com destaque para a expansão da oferta na Universidade Anhanguera-Uniderp.

A forte privatização, acompanhada da concentração da oferta em cursos de uma única área do conhecimento e da ampliação da área geográfica coberta, sem expansão significativa de concluintes no interior do Estado, indicam que a modalidade a distância não tem contribuído para a efetiva democratização do ensino no Estado de Mato Grosso do Sul, no sentido preconizado por este estudo. 
O caráter essencialmente mercadológico de algumas instituições que definem ações educacionais a partir de metas financeiras é denunciado, desde o início dos anos 2000, por pesquisadores brasileiros (SILVA JÚNIOR; SGUISSARDI, 2000; SGUISSARDI, 2008; SILVA FILHO, 2007; OLIVEIRA, 2009; CARVALHO, 2012), pois as ações regulatórias do Estado não têm sido suficientemente eficazes para deter o avanço do empobrecimento dos currículos e da grande rotatividade, criada em razão dos ciclos de demissões semestrais impostos aos profissionais da educação que atuam nestas empresas, bem como da troca constante de profissionais mais titulados e experientes por outros, menos titulados e menos experientes; portanto, profissionais estes, com salários mais baixos. A preocupação em maximizar lucros e gerar aumento de investidores nos fundos que financiam tais instituições se traduz em cortes nos investimentos para o ensino, a pesquisa e a extensão, e até mesmo na manutenção e na melhoria da infraestrutura.

Estas ações têm atingido fortemente o ensino superior, nas modalidades presencial e a distância, mas há maior preocupação com a modalidade a distância, pois há uma gama de pesquisadores (GIOLO, 2008, 2010; BARRETO, 2010; HYPOLITO, 2010) que questiona a possibilidade de esta modalidade propiciar a formação necessária aos estudantes. Acerca disto, cabe uma reflexão mais ampla, pois tomar a modalidade como o fator determinante para a baixa qualidade do ensino desenvolvido secundariza aspectos mais significativos, como as políticas institucionais, a organização do ensino e as suas condições de oferta. O que se observa, na primeira década dos anos 2000, é um preocupante processo de privatização e mercantilização da educação superior em ambas as modalidades.

Vale ressaltar que mesmo após a publicação da Lei n. ${ }^{\circ} 12.527$, de 18 de novembro de 2011 - conhecida como "Lei da transparência", que determina a garantia do direito ao acesso de informações das ações geradas nas instâncias públicas -, a ausência de transparência e publicização das avaliações em larga escala, que especifiquem os resultados de estudantes e cursos da modalidade a distância, bem como os resultados da supervisão e da regulação de cursos da modalidade a distância, por parte da Secretaria de Regulação e Supervisão da Educação Superior (SERES), permitindo a criação de séries históricas de dados, impede juízos de valor sobre a modalidade que estejam sustentados por resultados oficiais, o que dificulta a análise mais aprofundada da qualidade da oferta. Os pesquisadores estão momentaneamente limitados, portanto, ao mapeamento e à análise do processo de expansão da $\mathrm{EaD}$ e precisam lutar para que os dados oficiais tenham a transparência que a legislação exige. 


\section{Referências}

BARRETO, R. G. A formação de professores a distância como estratégia de expansão do ensino superior. Educação \& Sociedade, Campinas, v. 31, n. 113, p. 1299-1318, out./dez. 2010. Disponível em: < http://www.cedes.unicamp.br>. Acesso em: 7 maio 2012.

BRASIL. Ministério da Educação. Instituto Nacional de Estudos e Pesquisas Educacionais Anísio Teixeira. Censo da Educação Superior 2000: Resumo Técnico. Brasília, 2001.

. Instituto Nacional de Estudos e Pesquisas Educacionais Anísio Teixeira. Censo da Educação Superior 2001: Resumo Técnico. Brasília, 2002.

. Secretaria de Educação a Distância. Referenciais de qualidade da Educação a Distância. Brasília, 2007.

. Lista de polos credenciados para EaD. Brasília, 2009a. Disponível em:

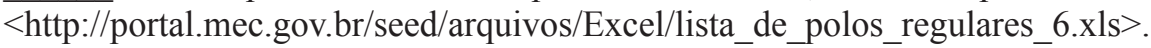
Acesso em: 23 jun. 2013.

. Instituto Nacional de Estudos e Pesquisas Educacionais Anísio Teixeira. Censo da Educação Superior: Sinopses Estatísticas: 2000 a 2008. Brasília, 2009 b. Disponível em: <http://portal.inep.gov.br/superior-censosuperior-sinopse>. Acesso em 31 ago. 2014.

. Instituto Nacional de Estudos e Pesquisas Educacionais Anísio Teixeira. Censo da Educação Superior 2009: Resumo Técnico. Brasília, 2010. Disponível em: $<$ http://www.inep.gov.br/download/superior/censo/2009/resumo_tecnico2009. pdf $>$. Acesso em: 10 mar. 2011.

. Instituto Nacional de Estudos e Pesquisas Educacionais Anísio Teixeira. Censo da Educação Superior 2010: Resumo Técnico. Brasília, 2011.

. Instituto Nacional de Estudos e Pesquisas Educacionais Anísio Teixeira. Censo da Educação Superior 2011: Resumo Técnico. Brasília, 2013a.

. Instituto Nacional de Estudos e Pesquisas Educacionais Anísio Teixeira. Censo da Educação Superior: Sinopses Estatísticas da Educação Superior: Graduação 2000-2012. Brasília, 2013b. Disponível em: <http://portal.inep.gov. br/superior-censosuperior-sinopse >. Acesso em: 31 ago. 2014. 
BRASIL. Instituto Nacional de Estudos e Pesquisas Educacionais Anísio Teixeira. Censo da Educação Superior 2012: Resumo Técnico. Brasília, 2013c.

. Instituto Nacional de Estudos e Pesquisas Educacionais Anísio Teixeira. Censo da Educação Superior 2012: Sinopse Estatística. Brasília, 2013d.

.E-mec. Mato Grosso do Sul: 2013. 2013e. Disponível em: $<$ http://emec. mec.gov.br>. Acesso em: 20 jul. 2013.

CARVALHO, C. H. A. A mercantilização da educação superior brasileira e as estratégias de mercado das IES lucrativas. In: REUNIÃO ANUAL DA ASSOCIAÇÃO NACIONAL DE PÓS-GRADUAÇÃO E PESQUISA EM EDUCAÇÃ̃O, 35., 2012, Porto de Galinhas, Pernambuco. Anais... Porto de Galinha: UFPA, 2012.

CASTRO, A. M. D. A.; CABRAL NETO, A. Educação a Distância como estratégia de expansão do ensino superior no Brasil. In: CHAVES, V. L. J.; CABRAL NETO, A.; NASCIMENTO, I. V. (Org.). Políticas para a educação superior no Brasil: velhos temas e novos desafios. São Paulo: Xamã, 2009. p. 85-108.

G1. Kroton e Anhanguera Educacional fazem acordo de associação. G1: Economia Negócios, 22 abr. 2013. Disponível em: <http://g1.globo.com/economia/negocios/ noticia/2013/04/rede-de-ensino-kroton-vai-incorporar-anhanguera-em-acordocom-acoes.html>. Acesso em: 30 abr. 2013.

GIOLO, J. A educação a distância e a formação de professores. Educação \& Sociedade, Campinas, v. 29, n. 105, p. 1211-1234, set./dez. 2008.

. Educação a Distância: tensões entre o público e o privado. Educação \& Sociedade, Campinas, v. 31, n. 113, p. 1271-1298, out./dez. 2010.

HYPOLITO, A. M. Políticas curriculares, Estado e regulação. Educação \& Sociedade, Campinas, v. 31, n. 113, p. 1337-1354, out./dez. 2010. http://dx.doi. org/10.1590/S0101-73302010000400015

INSTITUTO BRASILEIRO DE GEOGRAFIA E ESTATÍSTICA. Censo Demográfico 2010.Estados@Mato Grosso do Sul.2010a. Disponível em: <http:// www.ibge.gov.br/estadosat/perfil.php?sigla=ms>. Acesso em: 10 mar. 2013.

. Censo Demográfico 2010: Educação - Amostra. Estados@Mato Grosso do Sul. 2010b. Disponível em: <http://www.ibge.gov.br/estadosat/temas.php?si gla $=$ ms\&tema $=$ censodemog2010_educ $>$. Acesso em: 10 jul. 2013. 
INSTITUTO BRASILEIRO DE GEOGRAFIA E ESTATÍSTICA. PNAD - 2011. Estados@Mato Grosso do Sul. 2011. Disponível em: <http://www.ibge.gov.br/ estadosat $/$ temas.php?sigla $=\mathrm{ms} \&$ tema $=$ pnad_internet_celular_2011 $>$. Acesso em: 10 jul. 2013.

KROTON EDUCACIONAL; ANHANGUERA EDUCACIONAL PARTICIPAÇÕES. Fato Relevante. 22 abr. 2013. Disponível em: <http://www.bmfbovespa.com.br/ empresas/consbov/ArquivoComCabecalho.asp? motivo $=\&$ protocolo $=376786 \&$ funcao $=$ visualizar \&site $=B>$. Acesso em: 20 jul. 2013.

MAIA, Z. B. Expansão da Educação a distância no Brasil a partir dos anos 1990: o caso da Universidade do Tocantins - UNITINS. 2011. 297 f. Tese (Doutorado em Educação)-Universidade Federal de Góias, Goiânia, 2011.

OLIVEIRA, R. P. A transformação da educação em mercadoria no Brasil. Educação \& Sociedade, Campinas, v. 30, n. 108, p. 739-760, out. 2009. http:// dx.doi.org/10.1590/S0101-73302009000300006

ROSIN, C. A. B. A Educação a Distância no Brasil: limites e possibilidades na implantação da EaD no ensino superior. 2010. 113 f. Dissertação (Mestrado em Educação)-Faculdade de Humanidades e Direito, Universidade Metodista de São Paulo, São Bernardo do Campo, 2010.

SANTANA, A. F. R. Educação a Distância, Políticas Públicas e seus desdobramentos na formação dos professores de história. 2012. 143 f. Dissertação (Mestrado em História Social)-Universidade Federal de Uberlândia, Uberlândia, 2012.

SGUISSARDI, V. Modelo de expansão da educação superior no Brasil: predomínio privado/mercantil e desafios para a regulação e a formação universitária. Educação \& Sociedade, Campinas, v. 29, n. 105, p. 991-1022, dez. 2008. http://dx.doi. org/10.1590/S0101-73302008000400004

SILVA FILHO, R. L. L. et al. A evasão no ensino superior brasileiro. Cadernos de Pesquisa, São Paulo, v. 37, n. 132, p. 641-659, set./dez. 2007. Disponível em: $<$ http://www.scielo.br/pdf/cp/v37n132/a0737132.pdf>. Acesso em: 3 jul. 2008.

SILVA JÚNIOR, J. R.; SGUISSARDI, V. A educação superior privada no Brasil: novos traços de identidade. In: SGUISSARDI, V. (Org.). Educação superior: velhos e novos desafios. São Paulo: Xamã, 2000. p. 155-177.

SOMMER, L. H. Formação inicial de professores a distância: questões para debate. Em Aberto, Brasília, v. 23, n. 84, p. 17-30, nov. 2010. 
VOLPATO, L. A. A qualidade nos cursos de bacharelado em Administração a distância: um estudo comparativo nas principais IES privadas do Brasil. 2013. 384 f. Tese (Doutorado em Educação)-Pontifícia Universidade Católica de São Paulo, São Paulo, 2013.

\section{Expansion in Distance Higher Education in Mato Grosso do Sul state, Brazil, between 2000 and 2012 \\ Abstract}

In this article, we analyze the expansion of distance learning courses in the state of Mato Grosso do Sul, Brazil, characterize some types of undergraduate courses which are offered at distance by public and private institutions, and verify the access and equity of these offered courses in different knowledge areas. So far, two stages of the research have been carried out, including the surveying of the expansion of distance education courses in Mato Grosso do Sul state and in Brazil, between 2000 and 2012, through the analysis of data from the Higher Education Census, normative acts, information in the official databases of the Brazilian Ministry of Education (MEC), and institutional data. It is assumed that the expansion analyzed is conditioned by macroeconomic aspects and the form of organization of the Brazilian State, according to the determinations of capital. The results obtained point to the fact that the access to undergraduate courses was effectively instituted, with the offer of courses in all micro regions of Mato Grosso do Sul state, but more effectively in private institutions with focus on few knowledge areas, which does not characterize an effective democratization of this access.

Keywords: Distance Education. Undergraduate course. Expansion. Mato Grosso do Sul state. 


\section{Expansión en la Educación Superior a Distancia en Mato Grosso do Sul, en el período de 2000 a 2012 Resumen}

En este artículo se buscó analizar la forma de expansión de los cursos de graduación a distancia, en el estado de Mato Grosso do Sul (MS), así como: caracterizar los tipos de cursos de graduación ofrecidos en la modalidad a distancia, en las instituciones públicas y privadas, en MS; verificar el acceso y la equidad de oferta de cursos, en las diferentes áreas de conocimiento. Se realizaron, hasta el momento, dos etapas de investigación, abarcando el análisis de expansión de los cursos de graduación a distancia, en Brasil y en Mato Grosso do Sul, de 2000 a 2012, por medio del análisis de los datos del Censo de Educación Superior, actos normativos, informaciones en las bases oficiales del MEC y datos institucionales. Se parte de la perspectiva de que la expansión analizada está condicionada por los aspectos macroeconómicos y por la forma de organización del Estado brasileño, frente a las determinaciones del capital. Los resultados obtenidos señalan el hecho de que el acceso a los cursos de graduación se instituyó, efectivamente, con la oferta de cursos en todas las microrregiones del estado de MS, pero de forma más significativa, en instituciones privadas y concentradas en pocas áreas de conocimiento, lo que no caracteriza la efectiva democratización del acceso.

Palabras-clave: Educación a Distancia. Cursos de pregrado. Expansión. Mato Grosso do Sul.

\section{Informações da autora}

Carla Busato Zandavalli Maluf de Araujo: Professora Adjunta da UFMS. Doutorado em Educação. Contato: carlabzandavalli@gmail.com 